\title{
VIOLENCIA, AGRESIÓN Y DISCRIMINACIÓN EN LA ESCUELA. MIRADAS DESDE LAS MADRES DE FAMILIA DE SECTORES POPULARES DE LIMA
}

\author{
Pedro JACINTO PAZOS \\ Universidad Ricardo Palma \\ pedro.jacinto@urp.edu.pe
}

\section{RESUMEN}

En el siguiente artículo, trato de explicar cómo las madres de familia manifiestan las distintas formas de violencia y, los diferentes prejuicios de discriminación que se presentan en sus entornos vivenciales. En realidad, se trata de analizar desde la percepción que describen las madres de familia, las distintas formas de socialización que se instituyen desde los procederes, conductas o comportamientos que sus hijos expresan al interior de las instituciones escolares. Se estudian, las distintas maneras en que la agresión y la violencia escolar, se hacen presente desde sus relaciones más próximas, como son los ámbitos familiares, vecinales o barriales, desde un método cualitativo y con entrevistas a profundidad. El estudio se realizó en un colegio de Villa María del Triunfo y, otro de San Juan de Lurigancho.

\section{PALABRAS CLAVE}

Violencia, prejuicios, discriminación, escuela, Lima.

\section{VIOLENCE, AGGRESSION AND DISCRIMINATION IN THE SCHOOL. LOOKS FROM THE MOTHERS OF FAMILY OF POPULAR SECTORS OF LIMA}

\section{ABSTRACT}

In the following article, I try to explain how mothers express the different forms of violence and the different prejudices of discrimination that occur in their experiential environments. In fact, it is about analyzing from the perception that the mothers describe, the different forms of socialization that are instituted from the treatments, behaviors or behaviors that their children express within the school institutions. They study, the different ways in which aggression and school violence, are present from their closest relationships, such as family, neighborhood or neighborhood areas, from a qualitative method and with in-depth interviews. The study was conducted in a school in Villa María del Triunfo and another in San Juan de Lurigancho.

\section{KEY WORDS}

Violence, racist prejudices, school, Lima

Recibido: $12 / 03 / 2019$

Aprobado: 26/04/2019 


\section{Interrogantes preliminares}

L

os prejuicios son propios de nuestro sentido individual o social, que logra establecer juicios previos, clasificando, evaluando, juzgando y estereotipando bajo una jerarquía, a las poblaciones y personas desde el imaginario social'. Los prejuicios, conllevan una demarcación de la subjetividad que imprime conceptos, discursos, nombres, sobrenombres y calificativos a las personas u sociedades, que se piensan o se les endilga supeditación o, estatus social de dominado, por parte de quien lo mira u observa bajo significados de dominante. Mayormente, implican, los rasgos fisiológicos y/o físicos de los individuos o, también puede ser una denominación que se puede establecer para países, culturas completamente distintas del pre-juzgador. En sí, el prejuicio social, racial y cultural implica el pensarse diferente y se presenta como la persistencia en la alteridad de los seres humanos. Tiene sus antecedentes históricos en poblaciones que siempre se pensaron superiores o mantuvieron dominios de conquista o supremacía, como parte de sentirse principales. Esto, implica, también el concepto de discriminación racial, que engloba hoy en día todos los discursos y las distintas representaciones y prácticas sociales acerca de las diferencias y exclusiones sociales. Esto, no solo expresa, el sentido del color o del "olor", sino que involucra la explotación de millones de personas en el mundo entero. Es decir, se debe tener presente que todo ello conlleva relaciones de trabajo cuya primacía es de quienes lo detentan en el mundo. El sentido de dominación del pre-juzgador solamente piensa en su dominio desde sus ámbitos de poder. Pueden ser como cultura o etnia, pero también puede prejuzgarse racialmente como país. No en vano podemos decir que nuestra supremacía (o supeditación) fue provista de dos racionalidades que se ubicaban en antípodas distintas: el mundo europeo y el mundo latinoamericano. En sí, el nuevo mundo y el viejo mundo. Por lo tanto, la racionalidad implicó una racialización cuyo norte se explica por la colonialidad del pensamiento o las mentalidades y, que Europa instituyó desde su racionalidad instrumental en América Latina². Anotamos en sí, en nuestras reflexiones y desde nuestra investigación micro-cualitativa, los modos de violencia en la reproducción familiar, así como los estereotipos que se vienen imprimiendo en la vida escolar de los adolescentes. ¿Qué relación existe entre la violencia doméstica-familiar y barrial con las distintas formas de discriminación y agresión en la vida escolar? y; ¿De qué manera concurre la violencia desde los distintos modos de reproducción familiar y barrial en la escuela bajo los prejuicios discriminatorios y estereotipos racistas que se manifiestan en estos ámbitos?

Partimos de un supuesto exploratorio: los modos de reproducción familiar de los sectores populares, cuya génesis se percibe bajo condiciones precarias, fragiles y de exclusión social conllevan distintas manifestaciones socioculturales, cuyos discursos y sentidos de comunicación, se circunscriben a ciertos patrones socioculturales, que se manifiestan desde las distintas formas de violencia existentes a nivel familiar y

1 Parte del trabajo de investigación fue publicado en Ledesma (2019). Se trató solamente el caso de Villa María del Triunfo. Ver Bibliografía. Aquí también, quiero agradecer al Vicerrectorado de Investigación de la Universidad Ricardo Palma y el Vicerrectorado de Investigación Y Posgrado de la Universidad Nacional Mayor de San Marcos que hicieron posible la presente investigación, dentro de sus programas de investigación correspondientes a los años, 2017 y 2018.

2 Ver: Racismo. En: Ramírez, Eugenia (2011). Etnicidad, identidad, interculturalidad. Teoría, conceptos y procesos de la racionalidad grupal humana. Madrid. Editorial Universitaria Ramón Areces. 
barrial, que involucra a las mismas expresiones de agresión que se observan en la escuela, donde se establece también una mentalidad discriminatoria racial, producto de los estereotipos que se imprimen desde una imposición histórica y, una colonialidad simbólica excluyente y dominante que aún no se deja de lado $^{3}$. Hay que entender que, los insultos o el sentido peyorativo de las palabras o frases que se construyen a partir del prejuicio racista se van re-componiendo y reconstruyendo, a partir de los mismos sujetos sociales de manera constante $y$, desde una intersubjetividad naturalizada que la expresan cotidianamente y con mucha más constancia, los adolescentes, desde su vida escolar. Aquí, juega un papel importante la génesis del individuo, los entornos y el capital social y cultural sobre la cual se viene manifestando como sujeto-agente social.

Este es un avance descriptivo de lo que venimos investigando acerca de la relación de violencia, conflicto y racismo desde la escuela, pero esta vez visto por las madres de familia de la I.E. Soberana Orden Militar de Malta de Villa María del Triunfo en Lima. Y del colegio Toribio de Luzuriaga y Mejía de San Juan de Lurigancho. Son las madres de los alumnos del Quinto año de secundaria. Hemos trabajado con diez madres de familia en cada colegio, con entrevistas a profundidad semi-estructuradas y, a la vez expongo los resultados etnográficos del trabajo de campo realizado 4 . Quiero que se tenga presente que la idea de violencia, prejuicio y discriminación racista, se relacionan históricamente, como una persistente colonialidad propio de la supeditación a la que fue sometida América Latina desde el siglo XVI. Gran parte de las lógicas racionalistas que se piensan desterradas de la vida cotidiana de la gente, aún se manifiesta de manera perseverante. De este modo, parte de los términos o frases, que tratamos de-construir provienen de un pensamiento latente, donde aún se legitima un discurso que implican un poder ideológico, político y hasta religioso, donde la dominación se reitera por el lado de la intersubjetividad de las personas.

\section{Entre la violencia simbólica y la discriminación racial}

Existen determinadas formas de definir estas dos ideas. En realidad, son dos conceptos claves que recorren las distintas disciplinas, desde la psicología pasando por las ciencias sociales, hasta las ciencias médicas. Lo más importante en ello son las disímiles expresiones que se proponen como acepción, que implican, la violencia física, verbal y, psicológica. En unos casos, asumen el carácter del sujeto social a quien se le endilga el significado $y$, en otras, puede extenderse bajo, la violencia escolar, familiar, doméstica, sexual, cultural, política, religiosa, informativa, económica y, en casos más específicos el ciberbullyng o, en su sentido, subjetivo, la violencia simbólica, como lo categorizó Pierre Bourdieu, en varios de sus trabajos. Desde luego, no se asume pensando en la mentalidad o el pensamiento bajo una abstracción excluida del fenómeno social como tal, sino admitiendo la forma estructural que implican dichas ideas o símbolos que se concretizan en violencia o sevicia propias de la domesticidad o, del hogar familiar. En el caso peruano esto tiene su historia definida. La colonialidad e invasión territorial y forzada de nuestra 
población ha sido signada bajo estos parámetros durante varios siglos. Los procesos sociales han pautado un carácter social, cultural y étnico que han terminado por manifestar exclusión y discriminación en sus distintos aspectos. Bourdieu explica:

La violencia simbólica es, para expresarme de la manera más sencilla posible, aquella forma de violencia que se ejerce sobre un agente social con la anuencia de éste. (...) En términos más estrictos, los agentes sociales son agentes conscientes que, aunque estén sometidos a determinismos, contribuyen a producir la eficacia de aquello que los determina, en la medida en que ellos estructuran lo que los determina. (Bourdieu y Waqcuant, 1995: 120)

Desde luego, caracterizar lo simbólico como categoría es para asumirla, desde la relación social sobre la cual se desenvuelven las sociedades, las personas o los individuos. Es decir, es una expresión que encierra un significado, un lenguaje y un signo que conlleva el hecho social en su real dimensión. Implica un concepto donde los individuos se miran frente a frente para expresar sentidos de diferencia y de distinción jerárquica, que no se refieren en términos verbales pero que se endilgan en forma intersubjetiva. En el fondo, todos nos pensamos y nos exponemos mentalmente. En realidad, logramos nominaciones y categorías que solo el pensamiento lo prefija y lo sostiene del "uno" y del "otro". Por lo tanto, es entender que bajo dicha relación se encuentran relaciones de dominación, de supeditación y, de poder que de alguna forma se establecen entre los agentes sociales que la llevan a la práctica social. Es decir, entender que hay individuos que tratan de naturalizar su superioridad cuyos causales se desenvuelven bajo múltiples factores. Y no solo ello, sino de quienes piensan que dichos actos son propios y tienen que recibirse como tal, sin resistencia alguna. Es decir, la agresión o la violencia resignada. Naturalizada. En sí, son las maneras de entender los actos o acciones en la vida cotidiana de los individuos, desde las relaciones de trabajo y sus interacciones culturales o, étnicas, las que hacen posible distinguir los tipos de violencia. En esto, la psicología ha logrado encontrar distintas variantes de tal modo que ha tipificado las distintas manifestaciones, asumiendo su carácter permisivo, agresivo y, psicopatológico. Si lo asumimos, desde la sociología, se puede elaborar como parte de la violencia simbólica cuyas expresiones recorren las relaciones sociales intersubjetivas de los individuos o, las manifestaciones racionales de las personas que implica un proceso social cuya base se interioriza bajo un habitus y, una práctica social producto de una génesis cuya forma de dominio y subordinación se establecen constantemente. El habitus entendido como ese sentido histórico de asumir prácticas socio-culturales, que se interiorizan individualmente y se asumen, naturales por su imposición y por su agresividad. Se observa en la vida doméstica de los sectores populares regimentada por el Estado y legitimada desde los sectores conservadores de la religión católica desde tiempos de la colonia. En la vida doméstica, familiar y de matrimonio juega un papel importante la presión y la violencia de resignación que propone la iglesia católica durante más de dos mil años de existencia, desde su formas y normas patriarcalistas, que en el país y en América Latina, desde los inicios de la ocupación europea aún sigue vigente. La violencia en la familia ha necesitado de su regimentación y se puede sostener que la iglesia católica ha jugado un papel importante en esta forma de dominio y de violencia: 
La violencia simbólica es esa coerción que se instituye por mediación de una adhesión que el dominado no puede evitar otorgar al dominante $(y$, por lo tanto, a la dominación) cuando sólo dispone para pensarlo y pensarse o, mejor aún, para pensar su relación con él, de instrumentos de conocimiento que comparte con él y que, al no ser más que la forma incorporada de la estructura de la relación de dominación, hacen que ésta se presente como natural. (Bourdieu, 1999: 224-225)

Por lo tanto, la categoría conforme se evidencia en la vida cotidiana de los individuos, va cobrando significados cada vez más álgidos, sobre todo cuando su definición tiene un carácter racista o, por cuestiones de piel, y sobre todo comunicativo. En el fondo, es entender las formas en que se deconstruye el individuo para tipificarlo. No en vano los orígenes o las procedencias tienen su peso específico en todas estas relaciones. En sí, se ve una forma de violencia racial y racista, que muchas veces logra su incomprensión en las ciencias sociales, por tratar de construir una raza inexistente en términos de color y de genética. No obstante, más bien debemos de comprender, que se trata de una práctica social cuya interiorización por pensarse superior, desde el color, se ubica en lo socio-económico-cultural como distinción. Es decir, aglutina distintas formas causales pero cuyas maneras de atribuirse sentidos despectivos y, epítetos son propios de segregación y discriminación que muchas veces se dejan de lado por pensarse entre individuos del mismo origen, mismo color $y$, hasta lenguas comunes. Este es el dilema que implica lo teórico, no obstante, su discusión empírica se sucede en todos los ámbitos de la sociedad peruana.

Asumimos, por lo tanto, las ideas que sobre la violencia propone Bourdieu para expresar las interacciones sociales de los individuos, pero analizando el espacio social y el orden estructural en las que nos movilizamos. Es decir, comprendiendo que nuestro espacio social, sea como distinción y como estructura implica la familia, el barrio y la escuela, sobre todo donde el poder cobra múltiples aristas a pesar de entenderlo como poblaciones populares u homogéneas como parece suceder en el trabajo empírico:

Debido al hecho de que el espacio social está inscrito a la vez en las estructuras espaciales y las estructuras mentales, que son el producto de la incorporación de las primeras, el espacio es uno de los lugares donde se afirma y ejerce el poder, y sin duda en la forma más sutil, la de la violencia simbólica como violencia inadvertida: los espacios arquitectónicos -cuyas conminaciones mudas interpelan directamente al cuerpo y obtienen de éste, con tanta certeza como la etiqueta de las sociedades cortesanas, la reverencia, el respeto que nace de alejamiento o, mejor, del estar lejos, a distancia respetuosa- son en verdad los componentes más importantes, a causa de su misma invisibilidad, de la simbólica del poder y de los efectos totalmente reales del poder y simbólico» (Ibid: 122).

En el fondo, el autor, nos traslada a la escuela y al lugar de residencia para explicarnos cómo la violencia simbólica se va estableciendo, desde el espacio social y mental sobre la cual se van construyendo las relaciones de dominación y de poder desde una lógica estructural. Pero aquí, se tiene en cuenta que dicho dominio conlleva la idea de pensarlo legítimamente y aceptarla como tal.Y, sobre todo, las formas en que 
todo esto se reproduce familiarmente. Es que, aquí existe un modo de reproducción familiar de habitus como prácticas permanentes que se orientan históricamente y se consolidan como parte del orden de cosas, sobre la cual se encuentra el mundo estructural actual. En realidad un neoliberalismo capitalista imperial, que tiene nombre como sistema y como estructura. ¿De qué manera se relaciona esta idea de violencia doméstica-familiar con la discriminación racial y racista en países como los nuestros con sujetos, social, cultural e históricamente distintos a los europeos?

Cuando definimos discriminación, ésta también tiene distintas variantes que implican las diversas disciplinas, y puede explicarse desde lo racial-étnico hasta lo social. Centrado solamente, en lo que podría ser lo racial o racista, no se puede explicar bajo los términos que implican su sentido eurocéntrico situados en el color de la piel o la distinción black / White / brown. Esta distinción incluso desde la comunicación y la lengua, implican características denotativas de origen y de génesis. Es que, en el mundo latinoamericano y sobre todo el peruano, tiene un peso histórico el sentido de sumisión a la que fueron y son sometidas nuestras sociedades. Por lo tanto, el color tiene una impronta inicial, pero no determina bajo ninguna lógica el sentido de racialización étnica o, de diferencia que se ubican en nuestros países. En realidad, se puede hablar de intolerancia, exclusión, desprecio e insultos de lo que implica la mirada hacia el "otro" o la oposición que se manifiestan en las personas, pero no se pueden entender los sentidos de discriminación racista desde el sentido biológico o físico como lo pusieron en el tapete los grupos nacionalsocialistas en la Segunda Guerra Mundial. Cuando hablamos de discriminación racista estamos explicando las formas de pensarse desde el mundo de la colonialidad del saber y del pensamiento, donde lo étnico y lo cultural entrecruzan los orígenes de la naturalidad de los actos y de las relaciones sociales impuestas supuestamente por otros que se creyeron superiores o diferentes ${ }^{5}$. Es que, no se trata de la agresión constante que conlleva la vida física de los individuos sino tiene que manifestarse en términos intersubjetivos, donde las desigualdades se endilgan de manera ideológica y de enajenación.

\section{Madres de familia: Referencias generales}

Gran parte de las entrevistadas son mujeres. Mayormente, nacidas en Lima para el caso de VMT y de manera más heterogenea o regional para SJL. Todas ellas oscilan entre cuarenta y cincuenta años y son de religión católica. Y ya son los hijos de los migrantes de cuarta generación que se han constituido en Lima. En realidad, la situación de las madres de familia es de ser las principales tutoras o protectoras de los hijos, o las que asisten siempre a la escuela por la preocupación de los mismos. A estas alturas de los años, y a finales de la segunda década del siglo XXI, se puede decir que la escuela ha cambiado radicalmente en sus conductas y valores que se hace proclive mirar de distinta manera a los principales agentes partícipes de la educación, como son las madres de familia. Quizás, se puede decir que, los medios masivos de comunicación computarizados han logrado dar un giro en las diversiones y formas de socialización de los hijos que ya requieren de un cuidado muy especial por parte de los padres. Muchas de ellas, explican que asisten a la escuela a recoger a los hijos y de paso observar los comportamientos en que se encuentran los escolares. La

$5 \quad$ Ver Quijano, 1992. 
comunicación que tenemos a través de los medios acerca de la violencia, la agresión y el bulling es desde su forma más agresiva posible donde se observan las grandes reyertas a nivel de los alumnos. Incluso, muchas de las peleas escolares se difunden en gran parte de las redes sociales, que hace posible llamar la atención sobre las maneras en que la escuela proyecta una imagen de violencia donde el insulto queda atrás para hacer posibles agresiones físicas entre los escolares. Pero esto, no es propio de los alumnos, debemos de tener en cuenta que esto tiene sus causales en el entorno familiar, barrial, social y cultural sobre la cual se vienen formando estos adolescentes. Esta es la preocupación y lo que analizamos a continuación es la versión de madres de familia de escolares del colegio de Villa María del Triunfo y de San Juan de Lurigancho. Son veinte mujeres entrevistadas sobre quien logramos hacer la siguiente interpretación y análisis. En este caso tenemos madres de familia mayormente nacidas en Lima, católicas y ninguna dice hablar idioma nativo alguno. Como se ve son los sectores populares pobres y medios-pobres, donde gran parte de ellas, se dedican a trabajos precarios y a la domesticidad de la casa y la crianza de los hijos. Se podría decir, que ser ama de casa como lo refieren gran parte de las entrevistadas, es porque se presentan con parejas o esposos que se encargan de la economía de la casa, o se trata, también del desempleo o subempleo que recorre las relaciones de trabajo en el país. En realidad, los trabajos que demandan según las respuestas son de negocios en la calle, (ambulantes) o empleos de hogar. Lo que de algún modo hace referencia a sus orígenes en la Capital.

Tabla 1: Referentes generales de los entrevistados (VMT)

\begin{tabular}{|l|l|l|l|l|}
\hline \multicolumn{1}{|c|}{ Nombre } & \multicolumn{1}{|c|}{ Trabajo } & \multicolumn{1}{c|}{$\begin{array}{c}\text { Lugar de } \\
\text { Nacimiento }\end{array}$} & \multicolumn{1}{c|}{$\begin{array}{c}\text { Idioma } \\
\text { Materno }\end{array}$} & Religión \\
\hline 1. María (50) & Ama de casa (Negocio propio) & Bellavista, Callao & Castellano & Católica \\
\hline 2. Lucila (42) & Ama de casa & Lima & Castellano & Católica \\
\hline 3. Cintia (34) & Ama de casa & Lima & Castellano & Católica \\
\hline 4. María (39) & Ama de casa (Vendedora) & Piura & Castellano & Católica \\
\hline 5. Gladys (48) & Ama de casa (Vende golosinas) & Lima & Castellano & Católica \\
\hline 6. Rita (42) & Ama de casa (Desempleada) & Chimbote, Ancash & Castellano & Católica \\
\hline 7. Elizabeth (35) & $\begin{array}{l}\text { Ama de casa (Antes: empleo en } \\
\text { Casa) }\end{array}$ & Lima & Castellano & Católica \\
\hline 8. Martha (39) & Ama de casa & Loreto & Castellano & Católica \\
\hline 9. Janeth (49) & $\begin{array}{l}\text { Ama de casa. Antes: empleo } \\
\text { mercado }\end{array}$ & Lima & Castellano & Católica \\
\hline 10. Anita (52) & Cosmetóloga & Lima & Castellano & Católica \\
\hline
\end{tabular}

Fuente: Trabajo de campo. Noviembre 2017 - Marzo 2018.

Elaboración: Martín Barraza / Pedro Jacinto Pazos 
Tabla 2: Referentes generales de los entrevistados (SJL)

\begin{tabular}{|l|l|l|l|l|}
\hline \multicolumn{1}{|c|}{ Nombre } & \multicolumn{1}{|c|}{ Trabajo } & \multicolumn{1}{c|}{$\begin{array}{c}\text { Lugar de } \\
\text { Nacimiento }\end{array}$} & \multicolumn{1}{c|}{$\begin{array}{c}\text { Idioma } \\
\text { Materno }\end{array}$} & \multicolumn{1}{c|}{ Religión } \\
\hline 1. Lourdes (53) & $\begin{array}{l}\text { Ama de casa (Tiene puesto } \\
\text { de helados) }\end{array}$ & Lima & Castellano & Cristiana \\
\hline 2. María (38) & Ama de casa & Cusco & Castellano & Católica \\
\hline 3. María II. (45) & Ama de casa & Cerro de Pasco & Castellano & Cristiana \\
\hline 4.Janina (38) & Ama de casa & Lima & Castellano & Católica \\
\hline 5.Rosa (41) & Ama de casa & Huancavelica & Castellano & Católica \\
\hline 6.Lucinda (39) & Ama de casa & Junín - Tarma & Castellano & Católica \\
\hline 7.Teresa (54) & Ama de casa & $\begin{array}{l}\text { Ica - S.Vicente de } \\
\text { Cañete }\end{array}$ & Castellano & Cristiana \\
\hline 8.Yovana (34) & Ama de casa & Lima & Castellano & Católica \\
\hline 9.Elba (39) & Venta en mercado & Cajamarca & Castellano & Evangélica \\
\hline 10. Marcela (59) & $\begin{array}{l}\text { Ama de casa (vendedora } \\
\text { independiente) }\end{array}$ & Bellavista, Callao & Castellano & Evangélica \\
\hline
\end{tabular}

Fuente: Trabajo de campo. Noviembre 2017 - Marzo 2018.

Elaboración: Martín Barraza / Pedro Jacinto Pazos

\section{Violencia, agresión y racialización territorial: el "choloserraneo"}

Este es un tema reiterativo que venimos investigando y analizando en nuestras exploraciones en la diversidad de sujetos sociales que se nos presentan en el país. Lo hemos investigado en microempresarios, alumnos, consumidores, profesores y también mujeres-alumnas de los colegios. Todos tienen un sentido común en su expresión. Y, lo piensan como si fuere algo natural desde la lógica de la exclusión y la agresión. Todos lo miran desde los distintos ámbitos donde se encuentran, sea para diferenciarse o clasificarse socialmente. En realidad, distinción, jerarquía y sentidos de superioridad son lo primordial. Algunas veces se presenta como parte de la gracia o la jocosidad de la gente. Son pocos los que niegan su alcance en la gente y su manifestación discursiva racista. Proponemos estas palabras y frases, desde lo "cholo" y "serrano", como forma de distinción de lo que observamos en los imaginarios que se endilgan los mismos pobladores en su sentido social clasista. No lejos palabras que implican su contraste como lo "criollo" o "blanco". No lejos, En realidad, cómo lo "choloserraneo" tiene su vigencia histórica en la población latinoamericana y de preferencia peruana. Es por ello su contraste con la palabra "criollo" o "blanco". Aunque estas conllevan ya algunas relaciones epidérmicas, en algunos casos lo criollo ha denotado un sentido nada horizontal. Y, en otros, ha sido para reiterar el estigma que se les tiene. Desde luego, estas ideas fueron resultado de las lecturas que se observaban en los escritos del siglo XIX, en los clásicos de las ciencias sociales o las humanidades de entonces. No en vano, tenemos entre otros pioneros a autores como Sebastián Lorente (1851) y el mismo Clemente Palma (1905), sin contar la literatura que se veía en Felipe Pardo y Aliaga cuyo recalcitrante racismo recorría toda su pluma por esta época. Miremos sino la rima y el verso de la época donde se colocaban ideas racistas contra el Mariscal Santa Cruz, bajo estas 
palabras; serrano, cholo e, indio. Y en todo ello el negro. Lo mismo sucedió con su hijo Manuel. Una herencia racista desde la política, pero en sí, desde la literatura ${ }^{6}$. Es decir, el prejuzgamiento racial se ha instituido en la subjetividad o racionalidad de la gente. No solo se trata de verlo en el caso peruano desde sus pensamientos o discursos. También hay que tenerlo presente desde los países centros donde el color de la piel se presenta como referente de significado y de noción concreta frente a los distintos, o en todo caso, frente al extraño, exótico o el extranjero.

El objetivo es pensar cómo los distintos actores sociales lo tienen presente en su vida cotidiana desde su percepción con la cual se ubican frente a la escuela o en los distintos ámbitos en las cuales se orientan y manejan. En realidad, lo "cholo y lo serrano" son dos palabras cuasi naturalizadas en la concepción racista de la población que parece ser parte de un vocabulario permanente. En muchos casos aparece como: cholo = indio = serrano, en los mismos espacios territoriales que se les endilga y por los mismos pobladores originarios. O, lo aceptan, como parte de las narrativas desde el sentido común ya naturalizado bajo una idiosincrasia resignada de parte de quien lo recepciona o, tal vez implica cierto conflicto o resistencia para no asumirse racializado o excluido desde las lógicas del mismo peruano o copoblano. Diría que este es el dilema de gran parte de nuestra sociedad peruana. Pero, ¿Qué sentido tiene su comunicación desde lo agresivo y despectivo como se le escucha hoy en día, sobre todo en la escuela? La mentalidad peruana criolla colonial proveyó conceptos que se han propalado a lo largo de la historia, y ha llevado a pensarlos como parte del sometimiento de una cultura peruana enajenada. Tal vez podamos hablar aquí de una enajenación colonizada cuyo soporte sigue los traumas de la colonia europea-española, cuya forma de dominar es haciéndole rememorar al dominado que su espacio es el del servil-indígena que no puede "arrirmarse" al espacio dominante y criollo o elitista sobre la cual se ha construido la dominación del poder, y para ellos o "los otros" un estereotipo, una marca. No en vano podemos decir, que siempre se tuvo en la cabeza en el mundo andino peruano (se incluye la costa y amazonia peruana indígena) que el "arrimado" era el que se quería trepar en el ámbito social ajeno. En el fondo el que quiere treparse en la movilidad social ascendente que sola era propia de los criollos o de los que cuidaban de su poder económico o político. El servil siempre fue un individuo en casa y hacienda ajena. Esto es lo que pone en el tapete lo social. Por lo tanto, no puedes arrimarte, no puedes subirte al espacio social no correspondiente.

Es la historia la que nos precisa, una colonialidad que se mantiene incólume en las distintas esferas elitistas y de poder, pero a la vez también en espacios sociales bajos o populares, donde se supone frases que implican el "cholear o el serranear" como formas de distinción deben ser excluidas. Esto es lo más sintomático porque tenemos en sí, protagonistas que provienen de los sectores sociales populares o mejor decir, se explican desde una población social baja o media pobre que complejiza una situación racializada. Sus respuestas no pueden ser más significativas: "Todos somos cholos sin importar de donde seas"; "Una discriminación. Pero a veces los'cholos'son más inteligentes y trabajadores", "Una mezcla de razas. Depende del modo en que se dice, puede ser cariñoso o negativo" $y$, "Algo bonito. Todos los peruanos son cholos.

6 Mira el libro de Cecilia Mendez: "Incas sí, indios no", en Bibliografía. 
Nuestros antepasados de la Sierra"7. Es decir, en el fondo podemos no confundirnos y explicar que la distinción social y geográfica está bien marcada: Los cholos son los serranos pero a la vez son todos los peruanos. En realidad, podemos trabajar de distinto modo lo que se dice sobre la denominación de lo cholo, pero sigue siendo la gran causal de expresiones más duras y cruentas que se ven en la sociedad peruana. Por ello es que su extensión "cholo de mierda" sigue siendo la frase que se oye en la televisión, en la casa, en el colegio, en redes sociales, en el bus, en mercado, en el trabajo, en la calle, en La Molina, San Martin de Porres, Villa El Salvador, en todo sitio. No lejos de la palabra serrano y de la acepción "serrano de mierda" que se escucha en todos los ámbitos o lugares similares a los que encontramos para la palabra cholo ${ }^{8}$. Es decir, parece que no se distingue la idea. Ambas cholo y serrano están muy clavadas en la mentalidad de la gente. Y prácticamente, no se distingue de quiénes la pronuncian, sino que es un producto discursivo de todos los sectores sociales. $Y$ allí viene su complejidad por cuanto se piensa que debe de ser tratada desde determinados sectores sociales, cuando en realidad se ha diseminado socialmente en toda la población. No tenemos escapatoria cuando de diferencia se trata. Pero no de lo étnico o cultural sino de lo social. Se esgrime porque se ha logrado imponer como estatus y por lo tanto, ya no tienes el origen que implica la acepción. Al revés el origen, está tan clavado que la gente o por lo menos, los entrevistados no pueden negarlo, y mucho más, cuando el apellido o la firma se reiteran bajo el quechua o lo andino que no se quiere sacar a relucir.

En realidad, hablar de discriminación implica observar su complejidad y los factores causales que ella encamina. Y mucho más la violencia, la agresión y la prepotencia. Varios de los trabajos que se siguen realizando al respecto confirman la dureza con que se observan las formas de discriminación en la sociedad peruana. Se puede endilgar una manera racial o racista de pensar el prejuicio sobre todo cuando se tiene una subjetividad muy reelaborada sobre los epítetos o los estigmas que subyacen en los individuos o, en la escuela. Sin embargo, ésta debe de entenderse desde las lógicas que implican la agresión y la violencia en la familia. En el fondo, los temas que tratan sobre la familia vienen desde la psicología donde las causales se establecen como conductas inapropiadas o comportamientos cuyo origen proviene de una salud mental deteriorada. Desde luego, que es un factor, pero no el determinante ni decisivo para entender la sociedad y el sistema en el cual nos movilizamos. Puede ser, tanto de un causal de salud, pero a la vez implican una serie de causales donde lo económico también prima. Hay que tener en cuenta que los bienes de consumo que impone el capitalismo, son parte de un mundo del mercado donde los individuos en situación precaria no lo pueden adquirir. Esto implica, a la vez, también una relación social permanente donde los adolescentes lo sienten inalcanzable o en su defecto el trabajo sobre la cual se desenvuelven los padres o las madres que de alguna forma le va generando un cierto conflicto. Más si las relaciones de trabajo son completamente precarios o inexistentes en la que se ubican.

De este modo observamos, que las mujeres perciben distintas formas de violencia. Hacen una tipificación entre los verbal, físico y psicológico donde el "pegar a alguien"

7 Ver Jacinto $(2014,2016$ y 2019).

$8 \quad$ Ibid. 
o la "agresión" constante son evidentes. Donde los golpes y las palabras agresivas de los adultos hacia los niños, es una marca continua. Y las mujeres lo explican. Sobre todo, desde las alteraciones que se dan entre los padres: "Mucho resentimiento. Lo que absorben de familia. Se paga dentro del colegio". En sí, algo que no debe suceder, pero que, en realidad, se explica como algo: "Muy triste. Termina mal. Se da en violaciones, feminicidios, muertes $y$, suicidios". $Y$, desde luego, la falta de respeto o, la falta de comunicación que es lo que mayormente se reclaman. Se establece entonces, que estamos frente a una correlación de, cómo ciertos parámetros de la violencia simbólica y concreta desde el sentido del imaginario va encausando las formas de discriminación que se manifiestan entre las personas, y desde luego, explicarlas con una cierta naturalidad desde los sectores populares. Es decir, los que se endilgan en la calle desde una lógica racial se percibe o se construye desde la escuela o desde ámbitos cercanos a los padres: el hogar familiar. El sobreponer nombres o denominaciones raciales y racistas desde lo "cholo", "serrano", "negro", "queso", "llama" o, "alpaca", "chocolatito, cholo, sombra, serrano de m...., tiene mucho de connotación en las expresiones de los escolares, que salen a relucir en "los pleitos o las broncas" que ellos realizan.

De esta manera, se ha hecho tan común, estas formas de racialización que los pleitos o los golpes que se ven en la calle, a las salidas de los colegios, la agresión y las lisuras como parte de estos conflictos, tengan este sentido. Es decir, las lisuras verbales, los insultos, los apodos muchas veces pasan por estas formas de agredirse racialmente. Desde luego, bajo una agresión verbal donde la mentada de madre es común. Las madres, nos refieren, que incluso parte de esta agresión hace que los niños terminen en el hospital malherido y, con rencillas permanentes donde se reinician frases que refieren al ámbito de los animales. No en vano se pueden endilgar: "chanchito, calavera, tarado" o también: "shipiba, bruja, cerda, enana", o como dice Lucinda (39): "Cholo, serrano, negro, cabezón, gordo, kiwicha, bimbón", junto con los improperios desde las mentadas de madre y la misma agresión física. En realidad, todas las mujeres de ambos distritos investigados refieren esto. 
Tabla 3: Violencia, agresión y discriminación en el colegio (VMT)

\begin{tabular}{|c|c|c|c|c|}
\hline Nombre & \begin{tabular}{|c|} 
Frases \\
racistas en el \\
colegio
\end{tabular} & Formas de violencia & Agresión en colegio & $\begin{array}{l}\text { ¿Por qué se da } \\
\text { agresión en } \\
\text { colegio? }\end{array}$ \\
\hline 1. María (50) & \begin{tabular}{|l|} 
Chocolatito, \\
cholo, sombra, \\
serrano de m...
\end{tabular} & $\begin{array}{l}\text { Hay muchos tipos: física, } \\
\text { psicológica. }\end{array}$ & $\begin{array}{l}\text { Sí. Alumnos salen a } \\
\text { la calle y se agreden. } \\
\text { Verbal. Lisuras. }\end{array}$ & $\begin{array}{l}\text { Falta de respeto, } \\
\text { valores. Bullying. }\end{array}$ \\
\hline 2. Lucila (42) & Cuatrojos. & $\begin{array}{l}\text { Cuando le pegas a } \\
\text { alguien. Es agresivo. }\end{array}$ & $\begin{array}{l}\text { Se pelean en la salida. } \\
\text { Verbal en insultos. }\end{array}$ & $\begin{array}{l}\text { Porque están en } \\
\text { adolescencia. } \\
\text { Por chicas. Por } \\
\text { pelearse entre } \\
\text { grupos. }\end{array}$ \\
\hline 3. Cintia (34) & No ha oído. & $\begin{array}{l}\text { Algo que no debe } \\
\text { suceder en Perú. }\end{array}$ & $\begin{array}{l}\text { Se golpean, se dicen } \\
\text { palabras incoherentes }\end{array}$ & $\begin{array}{l}\text { No hay dialogo de } \\
\text { los padres hacia } \\
\text { los hijos. }\end{array}$ \\
\hline 4. María (39) & $\begin{array}{l}\text { Chola, cholo, } \\
\text { negro. }\end{array}$ & $\begin{array}{l}\text { Física, psicológica. Con } \\
\text { golpes o palabras. Entre } \\
\text { niños y adultos. }\end{array}$ & $\begin{array}{l}\text { No. Verbal sí. Insultos } \\
\text { y apodos. }\end{array}$ & $\begin{array}{l}\text { Conflictos en } \\
\text { partidos de futbol. } \\
\text { Una enamorada. }\end{array}$ \\
\hline 5. Gladys (48) & Nunguna & $\begin{array}{l}\text { Cuando un papá se } \\
\text { altera y le pega al niño. }\end{array}$ & No & $\begin{array}{l}\text { Por falta de } \\
\text { comunicación } \\
\text { entre los niños. }\end{array}$ \\
\hline 6. Rita (42) & $\begin{array}{l}\text { Shipiba, bruja, } \\
\text { cerda, enana }\end{array}$ & $\begin{array}{l}\text { Muy triste. Termina mal. } \\
\text { Se da en violaciones, } \\
\text { feminicidios, muertes, } \\
\text { suicidios. }\end{array}$ & $\begin{array}{l}\text { Bastante. Incluso } \\
\text { casos de niños que } \\
\text { acabaron en el } \\
\text { hospital. Agresión } \\
\text { verbal. }\end{array}$ & $\begin{array}{l}\text { Problemas del } \\
\text { hogar. Falta de } \\
\text { valores. }\end{array}$ \\
\hline 7. Elizabeth(35) & $\begin{array}{l}\text { Negro feo, } \\
\text { negro cochino. }\end{array}$ & $\begin{array}{l}\text { Falta de respeto, irse a } \\
\text { las manos. }\end{array}$ & $\begin{array}{l}\text { Física no. Verbal. } \\
\text { Insultos, apodos: } \\
\text { chanchito, calavera, } \\
\text { tarado. }\end{array}$ & $\begin{array}{l}\text { Por la educación } \\
\text { en casa. }\end{array}$ \\
\hline 8. Martha(39) & $\begin{array}{l}\text { Flaca, gorda, } \\
\text { negra, } \\
\text { charapa, } \\
\text { chanchas. }\end{array}$ & $\begin{array}{l}\text { Maltratar a niños, } \\
\text { gritarles, mandarles } \\
\text { toscamente. }\end{array}$ & $\begin{array}{l}\text { Sí, el año pasado } \\
\text { agredían a hijo. Sí, } \\
\text { verbal "concha tu } \\
\text { madre, contra". }\end{array}$ & $\begin{array}{l}\text { Observan a padres } \\
\text { y tías y repiten. }\end{array}$ \\
\hline 9. Janeth (49) & $\begin{array}{l}\text { Negro de } \\
\text { mierda }\end{array}$ & $\begin{array}{l}\text { Hay muchos tipos. } \\
\text { Verbal y física. Muy } \\
\text { dolorosas. }\end{array}$ & $\begin{array}{l}\text { Física sí, disimulada } \\
\text { entre juegos y } \\
\text { agresión. Golpes. } \\
\text { Verbal, insultos, } \\
\text { apodos: Llamar de "la" } \\
\text { a varones. }\end{array}$ & $\begin{array}{l}\text { Porque varones y } \\
\text { mujercitas se creen } \\
\text { mejor. Quieren } \\
\text { hacer sentir menos } \\
\text { al otro. }\end{array}$ \\
\hline 10. Anita (52) & $\begin{array}{l}\text { No logro } \\
\text { diferenciar por } \\
\text { costumbre } \\
\text { si es } \\
\text { discriminación } \\
\text { o cariño. }\end{array}$ & $\begin{array}{l}\text { Cuando los padres } \\
\text { maltratan a los niños. No } \\
\text { conversan. }\end{array}$ & $\begin{array}{l}\text { No mucho física. } \\
\text { Verbal, sí. Menta la } \\
\text { madre. }\end{array}$ & $\begin{array}{l}\text { Situación del } \\
\text { hogar. Imitan lo } \\
\text { que ven. }\end{array}$ \\
\hline
\end{tabular}

Fuente: Trabajo de campo. Noviembre 2017 - Marzo 2018.

Elaboración: Martín Barraza / Pedro Jacinto Pazos 
Tabla 4: Violencia, agresión y discriminación en el colegio (SJL)

\begin{tabular}{|c|c|c|c|c|}
\hline Nombre & $\begin{array}{l}\text { Frases racistas } \\
\text { en el colegio }\end{array}$ & $\begin{array}{c}\text { Formas de } \\
\text { violencia }\end{array}$ & Agresión en colegio & $\begin{array}{l}\text { ¿Por qué se da } \\
\text { agresión en colegio? }\end{array}$ \\
\hline 1. Lourdes (53) & "Cholo, negro" & $\begin{array}{l}\text { Verbal. } \\
\text { Física no he } \\
\text { observado. }\end{array}$ & $\begin{array}{l}\text { Agresión física no. Entre } \\
\text { alumnos pero verbal sí. } \\
\text { Insultos de acá para allá. }\end{array}$ & $\begin{array}{l}\text { Empiezan en broma y } \\
\text { terminan con apodos. Se } \\
\text { hacen gestos en forma } \\
\text { de puños. } \\
\end{array}$ \\
\hline 2. María (38) & "Serrano, chola" & $\begin{array}{l}\text { Golpes e } \\
\text { insultos. }\end{array}$ & $\begin{array}{l}\text { Agresión verbal, palabras } \\
\text { soeces. Burlas sobre los } \\
\text { rasgos físicos de los alumnos. }\end{array}$ & $\begin{array}{l}\text { Será, por enamorados, } \\
\text { de repente tienen algún } \\
\text { problema entre ellos. }\end{array}$ \\
\hline 3. María II. (45) & $\begin{array}{l}\text { "Yo soy de Lima, } \\
\text { tú eres cholito, tú } \\
\text { eres serrano" }\end{array}$ & $\begin{array}{l}\text { Violencia física } \\
\text { y verbal. }\end{array}$ & $\begin{array}{l}\text { Se pelean dentro y fuera del } \\
\text { colegio entre alumnos. Se } \\
\text { agreden con palabras soeces. }\end{array}$ & $\begin{array}{l}\text { Mucho resentimiento. } \\
\text { Lo que absorben de } \\
\text { familia. Se pega dentro } \\
\text { del colegio. }\end{array}$ \\
\hline 4. Janina (38) & $\begin{array}{l}\text { "Fea de mierda. } \\
\text { Cholo de mierda. } \\
\text { Patachueca, } \\
\text { muelona, nerd". }\end{array}$ & $\begin{array}{l}\text { Violencia física } \\
\text { y verbal. }\end{array}$ & $\begin{array}{l}\text { Varios chicos que se han } \\
\text { pegado. Lo hacen afuera. } \\
\text { Sea mujer u hombre. Dicen } \\
\text { groserías e insultos. }\end{array}$ & $\begin{array}{l}\text { Antes se peleaban por } \\
\text { una chica. Ahora, es } \\
\text { entre mujeres. "Porque } \\
\text { te miró mal." La otra se } \\
\text { cree más bonita. }\end{array}$ \\
\hline 5. Rosa (41) & $\begin{array}{l}\text { "Cholo, serrano, } \\
\text { negro, cabezón, } \\
\text { gordo, Tongo". }\end{array}$ & \begin{tabular}{|l|} 
Violencia y \\
agresión física \\
y verbal.
\end{tabular} & $\begin{array}{l}\text { Siempre hubo agresión. } \\
\text { También he presenciado } \\
\text { violencia verbal. }\end{array}$ & $\begin{array}{l}\text { Mucho insulto. Chica } \\
\text { contra una pareja. } \\
\text { Por temprana edad } \\
\text { de enamoramientos. } \\
\text { Conflictos. } \\
\end{array}$ \\
\hline 6. Lucinda (39) & $\begin{array}{l}\text { "Cholo, negro, } \\
\text { serrano, indio, } \\
\text { kiwicha, bimbón". }\end{array}$ & $\begin{array}{l}\text { Agresión física } \\
\text { y verbal. }\end{array}$ & $\begin{array}{l}\text { Bullying, puñetes, golpes. } \\
\text { No hay respeto. Se tratan } \\
\text { como ellos quieran. No por } \\
\text { su nombre. }\end{array}$ & $\begin{array}{l}\text { Por lo que pasan en el } \\
\text { hogar. Mucha violencia. }\end{array}$ \\
\hline 7. Teresa (54) & $\begin{array}{l}\text { "Negro, serrano, } \\
\text { indio, cholo, } \\
\text { chuncho." }\end{array}$ & \begin{tabular}{|l|} 
No he \\
observado \\
agresión física. \\
Verbal sí.
\end{tabular} & $\begin{array}{l}\text { Sí, se les escucha a los niños. } \\
\text { Del vocabulario que tienen. A } \\
\text { veces viene de casa mismo. }\end{array}$ & $\begin{array}{l}\text { Se dicen palabras } \\
\text { ofensivas. Se pelean, por } \\
\text { cualquier cosita. Como } \\
\text { en casa también, los } \\
\text { padres son así. }\end{array}$ \\
\hline 8. Yovana (34) & $\begin{array}{l}\text { "Charapa, negro, } \\
\text { indio, cholo, } \\
\text { gordo, panzón, } \\
\text { chato." }\end{array}$ & $\begin{array}{l}\text { Violencia física } \\
\text { y verbal. }\end{array}$ & $\begin{array}{l}\text { Pelean, afuera en pandillaje. } \\
\text { A veces están con cuchillo. } 0 \\
\text { pistolas. Se insultan. Como } \\
\text { dice, hay bullying. }\end{array}$ & $\begin{array}{l}\text { Se pelean por chicas. } \\
\text { Que el otro estuvo con } \\
\text { el otro y después con } \\
\text { el otro. Y entre ellos se } \\
\text { pelean. }\end{array}$ \\
\hline 9. Elba (39) & $\begin{array}{l}\text { "Tú eres negro. } \\
\text { Mira, yo soy } \\
\text { blanco","tus } \\
\text { padres son } \\
\text { serranos". } \\
\end{array}$ & $\begin{array}{l}\text { Verbal y } \\
\text { físicamente. }\end{array}$ & $\begin{array}{l}\text { Cuando el otro no lo respeta, } \\
\text { va al puñete. Jalón de pelo. } \\
\text { Eso es violencia. Insultos } \\
\text { como "eres un idiota", "nerd". }\end{array}$ & $\begin{array}{l}\text { Usted le dice una mala } \\
\text { palabra y a él no le } \\
\text { gusta. Y se va a generar, } \\
\text { pelea, golpe. En los } \\
\text { colegios. }\end{array}$ \\
\hline 10. Marcela (59) & No ha oído. & $\begin{array}{l}\text { Física sí. Verbal } \\
\text { no. El salón } \\
\text { de mi hija } \\
\text { tiene alumnos } \\
\text { respetuosos. }\end{array}$ & $\begin{array}{l}\text { Las mujeres son más } \\
\text { pleitistas. Se jalan los pelos, le } \\
\text { rompió acá, el ojo. Hinchada. } \\
\text { La otra arañada. Dice que } \\
\text { siempre hay esa pelea y la } \\
\text { droga la venden al fondo. }\end{array}$ & $\begin{array}{l}\text { Problemas que vienen } \\
\text { de casa. El papá se } \\
\text { separó, divorcio, o } \\
\text { maltrata a la mamá, y } \\
\text { desde niños ven esto. }\end{array}$ \\
\hline
\end{tabular}

Fuente: Trabajo de campo. Noviembre 2017 - Marzo 2018.

Elaboración: Martín Barraza / Pedro Jacinto Pazos 


\section{Agresión en la familia, la vecindad y el barrio}

La mirada sobre la violencia requiere de orientaciones, también, históricas que nos expliquen los sentidos causales y relacionales del fenómeno. En realidad, la violencia doméstica, para el caso peruano lo podemos remontar hasta tiempos coloniales: agresión, golpes, contusiones, muertes por la misma expoliación del trabajo doméstico. De hecho, violencia física y verbal por distintos causales sobre todo, en las misma familias señoriales y serviles. La historia nos endilga este proceso. Hay que ver, lo que se regimenta desde los matrimonios de entonces, y sobre todo la participación de la iglesia y el Estado que conllevaban gran parte de esta agresividad. No podemos sino explicar la fuentes de la historia peruana que evidencian el tratamiento matrimonial, el servilismo que se imponía a las mujeres, el abandono moral que se observaba a las mujeres que sufrían de dicha violencia. (Bustamante, 2018).

Como se sabe, esto lo tenemos todos los días -los medios de comunicación lo propalan a cada momento- $y$, por lo tanto, tiene sus actores sociales cuasi definidos. El hombre y la mujer en una lucha de género permanente. Las relaciones de poder, los niveles de enajenación y colonialidad sobre la cual se eleva nuestra razón y nuestras prácticas sociales tienen un continuun de agresión que no solo se expresa en lo físico, sino que se inocula desde ámbitos impensables. Es el hogar, es la escuela, es la calle, son todos los espacios de socialización donde observamos nuestros conflictos diarios. La escuela sigue siendo el espacio donde los sujetos sociales en acción dirimen sus expresiones de socialización, de afecto, de sensibilidad, pero a la vez también sus rencores, sus tirrias y sus desafíos a los maestros y a sus compañeros. Aquí se dan formas de des-socialización y de enconos que se manifiestan de manera intersubjetiva. Las expresiones de la investigación implican ello. Así, cuando a las madres de familia se les pregunta sobre la existencia de la agresión física en el hogar, ellas nos refieren que no han sido agredidas físicamente, no obstante, todas dicen que han recibido agresión verbal constantemente. Es decir, aquí se presentan los casos de negacionismo de algo que sucede frecuentemente, como dicen las mismas mujeres entrevistadas que, "sólo lo observamos, pero no me incumbe o nunca me ha sucedido". Es como la idea de la discriminación, sobre la cual se responde que nunca nos ha sucedido, pero sí se ve en otras personas. En el fondo, vemos en estas madres de familia un sentido de negar lo evidente.

Y, esto lo observan en el hogar, como "normal" o de forma natural "como en toda pareja", más cuando el, "Esposo alza la voz y la esposa le responde". Estos, son los momentos más álgidos en las parejas sobre todo cuando ya la discusión cobra un cariz mucho más agresivo. Aquí, no se refieren las palabras o frases que se dicen en el hogar, pero hay que tener presente que se trata también de expresiones que implican orígenes, modos de hablar, sentidos culturales y étnicos de la familia, en sí las características que recorren lisuras, adjetivos, epítetos y apodos, que para las mujeres son "normales", como nos refieren algunas entrevistadas. De hecho, que esto lo sostienen las mujeres y lo retrotraen a la escuela. Todos lo rememoran desde sus años de colegiales. Es decir, en el fondo es como si algo continuará bajo las mismas lógicas sobre las cuales como alumnas y hoy como madres se reconstruyeran. Aquí, 
la preocupación es porqué dicen que nunca fueron agredidas físicamente. Quizás podamos ver una represión para pensarse "no agredidos" por las razones de no ser etiquetadas o tipologizadas como violentas o familias con violencia permanente. De todos modos, existen algunas madres de familia que reconocen el sentido físico de la agresión familiar, pero no en ellas sino en amigas o parientes. Es decir, estamos ante una encrucijada donde muchas veces no queremos reconocer agresión propia, pero si ajena, porque "lo ví en amigas" o también porque "me lo contaron". Esto es el no reconocimiento de algo que se acumula y termina en actos más perniciosos de las personas por no hablar de la violencia homicida o feminicida que recorre el país. Es el momento de explicarlo como el sentido estructural de una sociedad que hace brechas frente a una modernización que fue hecha para la civilización, la no agresión y para la libertad de las personas. En realidad, el mundo del neoliberalismo tiene que reconocer que sus consecuencias no solo implican las relaciones económicas sobre la cual se construye y se manifiesta el individuo, las personas o la sociedad sino tiene que explicar, también que agrede y destruye ámbitos íntimos de la racionalidad de las personas o de las sociedades. El pensamiento también entra en confrontación.

Cuando se les pregunta ¿Por qué se da la agresión en el hogar? Nos dicen, porque "Se perdió el respeto", por "El dinero y los conflictos de pareja"; "porque no se comprenden"; "No hay respeto mutuo ni comunicación entre la pareja", "No hay trabajo", por la "Seguridad y confianza de pareja. Por la formación en casa" o por "Pelea de hogar y padres separados". O, los que nos responden las mamás de SJL: "Hay mucho engaño. El matrimonio no se respeta. Por adulterio, fornicación. La que más hay violencia. O por el dinero", “Porque son de padres separados. Y los papás en casa discutimos también por falta de dinero, el hijo escucha, hay adolescentes que les choca más. A otros no."

De hecho, que todo confluye, el trabajo, la economía, la incomunicación y la disfuncionalidad de las parejas. En el fondo, sigue siendo el trabajo lo que conlleva dinero, consumo y sobrevivencia. Estamos en los sectores populares de Lima y ellos lo miran de esa manera. No dejan de ver el sentido causal de un fenómeno que llega a la escuela y se dispersa desde el hogar, pasan por las relaciones de género, por la pareja, la convivencia cuyas prácticas sociales pueden conllevar incomunicación y desconfianza. Y desde luego, lo que se construye en el barrio, en la calle donde la violencia es el caldo de cultivo de relaciones precarias, desde los vecinos que se tiran piedras o se agreden y de la escuela que es parte de todo esto. Se puede ver tanto en la familia como en las pandillas, parecen no distinguirlo, pero su recorrido como violencia es evidente. Las razones son de todo tipo. El dinero cobra su función, los jóvenes están presentes, se superpone la familia y desde luego, el alcohol por no decir, las drogas que complementan las causas conflictuales y de violencia que se reproduce en la escuela. Y una de las madres (Rita, 42) lo sintetizó mejor: las deudas económicas. Y la agresión en el barrio nos conducen a las mismas respuestas. 
Tabla 5: Violencia en el hogar y el barrio (VMT)

\begin{tabular}{|c|c|c|c|c|}
\hline Nombre / Tema & $\begin{array}{c}\text { Agresión física en } \\
\text { hogar }\end{array}$ & $\begin{array}{l}\text { ¿Por qué se da } \\
\text { agresión en } \\
\text { hogares? }\end{array}$ & $\begin{array}{l}\text { ¿Agresión en el } \\
\text { barrio? }\end{array}$ & $\begin{array}{c}\text { ¿Por qué se da } \\
\text { agresión en barrio? }\end{array}$ \\
\hline 1. María (50) & $\begin{array}{l}\text { No. Verbal sí, lo } \\
\text { normal en un } \\
\text { hogar. }\end{array}$ & $\begin{array}{l}\text { Se perdió el respeto. } \\
\text { El dinero. Conflictos } \\
\text { de pareja. }\end{array}$ & Sí, de familias. & $\begin{array}{l}\text { No lo sé, pero hay } \\
\text { conflicto por muchas } \\
\text { razones. Incluso por } \\
\text { estacionar el auto. }\end{array}$ \\
\hline 2. Lucila (42) & $\begin{array}{l}\text { No. Verbal sí. } \\
\text { Esposo alza la } \\
\text { voz y esposa le } \\
\text { responde. } \\
\end{array}$ & $\begin{array}{l}\text { Por falta de dinero, } \\
\text { porque no se } \\
\text { comprenden. }\end{array}$ & $\begin{array}{l}\text { Los alumnos que } \\
\text { salen. Los vecinos, } \\
\text { no. }\end{array}$ & No he observado. \\
\hline 3. Cintia (34) & $\begin{array}{l}\text { Hace años cuando } \\
\text { iba al colegio. }\end{array}$ & $\begin{array}{l}\text { No hay respeto } \\
\text { mutuo ni dialogo. }\end{array}$ & $\begin{array}{l}\text { Los vecinos se } \\
\text { pelean en la calle. } \\
\text { Los pandilleros. }\end{array}$ & $\begin{array}{l}\text { Pandilleros agreden } \\
\text { a chicos de la cuadra. } \\
\text { Cuadra a cuadra se } \\
\text { enfrentan. }\end{array}$ \\
\hline 4. María (39) & $\begin{array}{l}\text { Años atrás cuando } \\
\text { estábamos en } \\
\text { colegio. }\end{array}$ & $\begin{array}{l}\text { Falta dinero, } \\
\text { problemas de pareja, } \\
\text { separación, no hay } \\
\text { trabajo. }\end{array}$ & No. Solo verbal. & $\begin{array}{l}\text { Física no. Verbal, } \\
\text { problemas entre } \\
\text { vecinos y la junta } \\
\text { directiva. Reclamos } \\
\text { fuertes. } \\
\end{array}$ \\
\hline 5. Gladys (48) & No & $\begin{array}{l}\text { Por falta de } \\
\text { comunicación entre } \\
\text { la pareja. }\end{array}$ & No & \begin{tabular}{|l} 
Padres no se \\
comunican con los \\
niños. Se separan y \\
juntan con pandilleros.
\end{tabular} \\
\hline 6. Rita (42) & $\begin{array}{l}\text { No. Pero amigas sí. } \\
\text { Agresión verbal en } \\
\text { su propio hogar sí. }\end{array}$ & $\begin{array}{l}\text { Condiciones } \\
\text { económicas. } \\
\text { Seguridad y confianza } \\
\text { de pareja. Formación } \\
\text { en casa. }\end{array}$ & $\begin{array}{l}\text { No mucho. En } \\
\text { anterior barrio sí. } \\
\text { Entre transeúntes. } \\
\text { Discusiones y } \\
\text { pleitos. }\end{array}$ & $\begin{array}{l}\text { Por dinero, deudas. } \\
\text { Perros que dañan } \\
\text { propiedad ajena o } \\
\text { desparraman basura. } \\
\text { Riñas entre familias. }\end{array}$ \\
\hline 7. Elizabeth (35) & $\begin{array}{l}\text { No. Ni física ni } \\
\text { verbal. }\end{array}$ & $\begin{array}{l}\text { Porque se permite } \\
\text { desde un primer } \\
\text { momento y se vuelve } \\
\text { rutinaria. }\end{array}$ & \begin{tabular}{|l|} 
Pandilleros y \\
grupos que se \\
pelean entre ellos.
\end{tabular} & $\begin{array}{l}\text { Pandillaje, personas de } \\
\text { mala vida. }\end{array}$ \\
\hline 8. Martha (39) & No. & $\begin{array}{l}\text { Pelea de hogar, } \\
\text { padres separados. }\end{array}$ & \begin{tabular}{|l|} 
Sí. Entre vecinos \\
se tiran piedras, \\
golpean e insultan. \\
\end{tabular} & $\begin{array}{l}\text { No saben controlarse } \\
\text { en hogar, }\end{array}$ \\
\hline 9. Janeth (49) & $\begin{array}{l}\text { No. Verbal en } \\
\text { familia no. Sí en } \\
\text { parientes. }\end{array}$ & $\begin{array}{l}\text { Mujeres callan } \\
\text { desde el inicio. } \\
\text { Incomunicación en } \\
\text { la pareja. Descuido. } \\
\text { Pero se supera } \\
\text { conversando. }\end{array}$ & $\begin{array}{l}\text { Toman y luego se } \\
\text { tiran la botella, } \\
\text { golpes, insultos. }\end{array}$ & $\begin{array}{l}\text { Por el alcohol, la } \\
\text { agresión incluso entre } \\
\text { familia, sin darse } \\
\text { cuenta. }\end{array}$ \\
\hline 10. Anita (52) & $\begin{array}{l}\text { Física, muy poco. } \\
\text { Levantar la voz. }\end{array}$ & $\begin{array}{l}\text { Por padres separados, } \\
\text { situación económica. }\end{array}$ & $\begin{array}{l}\text { Física, sí. Los } \\
\text { que paran en las } \\
\text { esquinas. }\end{array}$ & $\begin{array}{l}\text { La situación de la vida. } \\
\text { Parar en la esquina. }\end{array}$ \\
\hline
\end{tabular}

Fuente: Trabajo de campo. Noviembre 2017 - Marzo 2018.

Elaboración: Martín Barraza / Pedro Jacinto Pazos 
Tabla 6: Violencia en el hogar y el barrio (SJL)

\begin{tabular}{|c|c|c|c|c|}
\hline $\begin{array}{l}\text { Nombre I } \\
\text { Tema }\end{array}$ & $\begin{array}{c}\text { Agresión física en } \\
\text { hogar }\end{array}$ & $\begin{array}{c}\text { ¿Por qué se da agresión en } \\
\text { hogares? }\end{array}$ & $\begin{array}{c}\text { ¿Agresión en el } \\
\text { barrio? }\end{array}$ & $\begin{array}{c}\text { ¿Por qué se da } \\
\text { agresión en barrio? }\end{array}$ \\
\hline 1. Lourdes (53) & $\begin{array}{l}\text { Estoy separada del } \\
\text { papá de mis hijitos. Yo } \\
\text { vivo tranquila. }\end{array}$ & $\begin{array}{l}\text { Hay papás que pegan a sus parejas. } \\
\text { Las señoras un poco agresivas. En el } \\
\text { barrio y centro educativo también } \\
\text { debe haber. Niños son de padres } \\
\text { separados. }\end{array}$ & $\begin{array}{l}\text { En el barrio sí. Gente } \\
\text { de otro lado que } \\
\text { vienen y buscan } \\
\text { pelea. }\end{array}$ & $\begin{array}{l}\text { Los que toman. De allí } \\
\text { vienen los problemas. }\end{array}$ \\
\hline 2. María (38) & No ha observado. & No sabría decir. & No ha observado & $\begin{array}{l}\text { No sabría decir porque } \\
\text { no ha observado. }\end{array}$ \\
\hline 3. María II. (45) & $\begin{array}{l}\text { Hay mucha violencia } \\
\text { dentro de la familia. } \\
\text { Está aumentando } \\
\text { de más. }\end{array}$ & $\begin{array}{l}\text { Hay mucho engaño. El matrimonio } \\
\text { no se respeta. Por adulterio, } \\
\text { fornicación. La que más hay } \\
\text { violencia. O por el dinero. }\end{array}$ & $\begin{array}{l}\text { Física, en el barrio. } \\
\text { Jovencitos se } \\
\text { Agredieron, se } \\
\text { metieron botella. } \\
\text { Murió el muchacho. }\end{array}$ & $\begin{array}{l}\text { La familia no está, cerca } \\
\text { de sus hijos. Influencia } \\
\text { de malas amistades. } \\
\text { Aprendan a buscar sus } \\
\text { amistades. }\end{array}$ \\
\hline 4. Janina (38) & No, ni verbal ni física. & $\begin{array}{l}\text { Porque son de padres separados. } \\
\text { Y los papás en casa discutimos } \\
\text { también por falta de dinero, el hijo } \\
\text { escucha, hay adolescentes que les } \\
\text { choca más. A otros no. }\end{array}$ & \begin{tabular}{|l|} 
Sí. Agresión física. \\
Se pelean a veces \\
entre vecinos, entre \\
los hijos. Se meten \\
la mano. Se van a los \\
golpes. \\
\end{tabular} & $\begin{array}{l}\text { A veces en el barrio } \\
\text { porque ensucian la } \\
\text { vereda. El niño rompe } \\
\text { la planta y se molesta } \\
\text { la mamá. }\end{array}$ \\
\hline 5. Rosa (41) & $\begin{array}{l}\text { Domestica sí. Yo lo he } \\
\text { pasado. No puedes } \\
\text { permitir esa agresión. } \\
\text { También verbal. El } \\
\text { tema es el dinero. Yo } \\
\text { evito discutir. Uno se } \\
\text { enferma con todos } \\
\text { esos problemas. }\end{array}$ & $\begin{array}{l}\text { Causa por falta de diálogo. A } \\
\text { veces de comprensión. Pero si hay } \\
\text { familias que como padres han } \\
\text { vivido en conflictos. Eso da el reflejo } \\
\text { a los hijos. }\end{array}$ & $\begin{array}{l}\text { Siempre hay en el } \\
\text { barrio. Agresión } \\
\text { físico. No falta una } \\
\text { reunión que sale } \\
\text { peleando. Con } \\
\text { botellas. Son de otro } \\
\text { sitio. }\end{array}$ & $\begin{array}{l}\text { Conflictos hay muchos. } \\
\text { Observa que roban } \\
\text { celulares. Vienen de } \\
\text { otros barrios. Yo vivo } \\
\text { en Mártires. En la } \\
\text { parte de la Cruz, ahí se } \\
\text { estacionan. Por malos } \\
\text { amigos. El barrio ya se } \\
\text { malogró. }\end{array}$ \\
\hline 6. Lucinda (39) & No, ni física ni verbal. & $\begin{array}{l}\text { Porque no hay comunicación en } \\
\text { familia. Hay mucha violencia. Por } \\
\text { borracho. Y comienza a agredir. }\end{array}$ & \begin{tabular}{|l|} 
Las personas que \\
toman. En las fiestas, \\
Se agreden con \\
botellas, patadas, \\
puñetes
\end{tabular} & $\begin{array}{l}\text { Peleas, pero no lo hacen } \\
\text { sano. Esperan tomarse y } \\
\text { ahí viene el problema. }\end{array}$ \\
\hline 7. Teresa (54) & $\begin{array}{l}\text { Física no. Verbal, entre } \\
\text { mis hijos a veces. }\end{array}$ & $\begin{array}{l}\text { A veces por factor económico. } 0 \text { a } \\
\text { veces las infidelidades entre pareja. }\end{array}$ & No he observado. & $\begin{array}{l}\text { Casi muy poco veo esas } \\
\text { cosas. Porque, como yo } \\
\text { le digo, trabajo. Bueno, } \\
\text { infidelidades se ven en } \\
\text { todo sitio. }\end{array}$ \\
\hline 8. Yovana (34) & No. Ni verbal, ni física. & $\begin{array}{l}\text { Porque no hay comprensión entre } \\
\text { parejas. Hay mucha delincuencia. } \\
\mathrm{O} \text { a veces el hombre se va con otra } \\
\text { mujer. }\end{array}$ & \begin{tabular}{|l|} 
Los niños, los \\
adolescentes, sí. Sí, \\
hay mucha agresión. \\
En estos momentos. \\
\end{tabular} & $\begin{array}{l}\text { Ahí así, de familia. } \\
\text { Cuando toman así } \\
\text { de pareja. Así veo la } \\
\text { violencia }\end{array}$ \\
\hline 9. Elba (39) & $\begin{array}{l}\text { Física no. Verbal sí, hijo } \\
\text { con sus padres. }\end{array}$ & $\begin{array}{l}\text { Falta de comunicación. Los padres } \\
\text { no hacemos caso a los hijos. Eso } \\
\text { también genera violencia, también. } \\
\text { O el familiar que no le haces caso. }\end{array}$ & $\begin{array}{l}\text { He observado } \\
\text { agresión en mi } \\
\text { barrio. }\end{array}$ & $\begin{array}{l}\text { A veces por celos. El } \\
\text { esposo con la esposa. } \\
\text { Mayormente es por eso. }\end{array}$ \\
\hline 10. Marcela (59) & $\begin{array}{l}\text { [Mi vecino] es policía } \\
\text { y la señora se dicen } \\
\text { de todo. A su hijo, } \\
\text { le menta. Ratero, } \\
\text { delincuente. A su hija } \\
\text { "lárgate a trabajar". } \\
\text { Pero la chiquita como } \\
\text { media especial, es así. }\end{array}$ & $\begin{array}{l}\text { Están los celos. El licor. Los infieles } \\
\text { a veces se aburren de la mujer. Hay } \\
\text { mujeres que les pegan, les dan } \\
\text { duro. Denuncian, y por mantener al } \\
\text { hijito la anulan. Me acostumbro a } \\
\text { que me estén dando. Y, otro, que te } \\
\text { llena de hijos. }\end{array}$ & $\begin{array}{l}\text { No. Vivo en la villa, } \\
\text { en Angomarca. } \\
\text { Todos los chicos son } \\
\text { profesionales. Con } \\
\text { ellos mi hijo juega } \\
\text { futbol. }\end{array}$ & $\begin{array}{l}\text { Viene de las barras } \\
\text { bravas, los famosos } \\
\text { de la Alianza y U. Ayer } \\
\text { nomás ha habido un } \\
\text { problema con balas. } \\
\text { Es por el alcohol, más } \\
\text { que todo }\end{array}$ \\
\hline
\end{tabular}

Fuente: Trabajo de campo. Noviembre 2017 - Marzo 2018.

Elaboración: Martín Barraza / Pedro Jacinto Pazos 


\section{CONCLUSIONES}

1. Existe una relación directa entre la violencia simbólica, agresión física y la discriminación socio-cultural que se manifiesta en la educación básica constantemente. Se encuentran espacios sociales que confluyen y se encausan de manera institucional desde una continua violencia que las respuestas o la solución a dichos problemas por parte del Estado son irreales. Papel importante juega, el hogar familiar, el barrio, los vecinos, los jóvenes y adolescentes alumnos junto a los maestros o profesores en dicha problemática. En realidad, lo que se manifiesta en el hogar muchas veces se queda en las cuatro paredes que incluso la investigación de dicho ámbitos, necesita de la objetividad del trabajo de campo y de las formas de concretizar el hecho bajo otras perspectivas. En el fondo, la metodología.

2. Un elemento esencial, sobre la cual se basa el trabajo empírico, es la percepción de las madres de familia que se deriva como partícipes de los hechos y de la violencia que experimentan o que dicen ellas mismas no sucederles, pero que testifican muchas veces para los vecinos o los que "conocen" en el barrio. Esto no solo va explícito bajo la agresión sufrida en el hogar, sino la manera de percibirlos en los amplios espectros del barrio. En realidad, una forma de explicarlo, implica el dolor, el desgarro familiar y la agresión que se traslada hacia los hijos y de allí hacia la escuela. Si bien se necesita de prescindir de todo ello. La violencia física y verbal se ha naturalizado que las madres de familia lo ven como parte de la vida cotidiana. Las relaciones disfuncionales y el encause o comportamiento de los hijos termina derivando en las relaciones de los padres o de los hermanos que terminan reprobando un hecho muy alarmante, de acuerdo a los testimonios.

3. Se puede inferir de igual manera que el sentido de dominio y de exclusión sea por parte de los padres o la vecindad-barrial, cobra su manifestación esclarecida en la escuela. La agresión va con ella. Los sentidos de causalidad de esta violenciadominio, se reproduce en las prácticas sociales cotidianas del hogar, la familia, las relaciones de trabajo, la vecindad y el barrio como formas de construcción de rivalidades y enfrentamientos perniciosos, poco constructivos en su sentido de confianza y convivencia. En el fondo, familias entre sí, o inter-vecinales e, inter-barriales se explican como los generadores de dicha violencia. Gran parte de dichas prácticas tienen su reproducción en la escuela. De hecho, todo confluye para explicarnos la violencia escolar: la economía, la incomunicación familiar-vecinal y la disfuncionalidad y/o desestructuración de las parejas. No lejos de todo ello, el desempleo o la precariedad del trabajo que conlleva dinero, consumo y sobrevivencia. Y las mujeres lo explican de manera objetiva, no ocultando el espacio estructural en la que se desenvuelven. Un mundo de consumo que conlleva sus consecuencias en la agresión escolar.

4. Estamos en los sectores populares de Lima y las madres de familia tienen su percepción singular. Las razones son de todo tipo. El dinero cobra su función, los jóvenes están presentes, se superpone la familia y desde luego, el alcohol por no decir, las drogas que complementan las causas conflictuales y de agresión que se reproduce en la escuela. Esto no quiere decir que solamente se manifieste 
en los sectores populares y, donde se produce dicha reacción. Desde luego, se cruza en los distintos espacios sociales con distinto carácter, incluso, donde la violencia simbólica hace su cauce y es mucho más agresivo porque conlleva el racismo y la discriminación a cuestas. En realidad, la escuela mantiene comportamientos y acción social que se generan en el calor del hogar.

\section{REFERENCIAS BIBLIOGRÁFICAS}

Bourdieu, P. y L. Wacquant (1995). Respuestas. Por una antropología reflexiva. Barcelona: Anagrama.

Bourdieu, P. (1999). Meditaciones pascalianas. Barcelona: Anagrama.

Bustamante, L. (2018). Matrimonio y violencia doméstica en Lima colonial-1795-1820. Lima: IEP / Universidad de Lima.

Jacinto, P. (2019). Violencia y prejuicios racistas en la escuela. Una perspectiva desde las madres de familia de Villa María del Triunfo. Lima. En: Marianella Ledesma (Coordinadora). Justicia y Educación. Saberes y prácticas inclusivas en América y Europa. (537-560). Lima. Perú: Centro de Estudios. Tribunal Constitucional del Perú.

(2016). Discriminación racial y racista en la educación Peruana. Revista Investigaciones Sociales. 20 (36), 15-25. doi.org/10.15381/is.v20i36.12989

(2014). Sobre la subjetividad racial y racista en la educación Peruana. Revista Yuyaykusun. 7, URP. Departamento de Humanidades. 265-275 DOI: https://doi.org/10.31381/yuyaykusun.v0i7.220

Lorente, S. (?/1855). Pensamientos sobre el Perú. Lima: UNMSM.

Méndez, C. (2011). De indio a serrano: nociones de raza y geografía en el Perú. (Siglo XVIII al XXI). Rev. Histórica. 35 (1), 53-102.

Quijano, A. (1992). Colonialidad y Modernidad/ Racionalidad. Revista Perú Indígena. 13 (29) 11-20. Lima: IIP.

(1993). Raza, etnia y nación en Mariátegui. En: José Carlos Mariátegui y Europa. El otro aspecto del descubrimiento. Lima. Perú: Editora Amauta. 167 - 189.

Ramírez, E. (2011). Etnicidad, identidad, interculturalidad. Teoría, conceptos y procesos de la racionalidad grupal humana. Madrid. Editorial Universitaria Ramón Areces. 